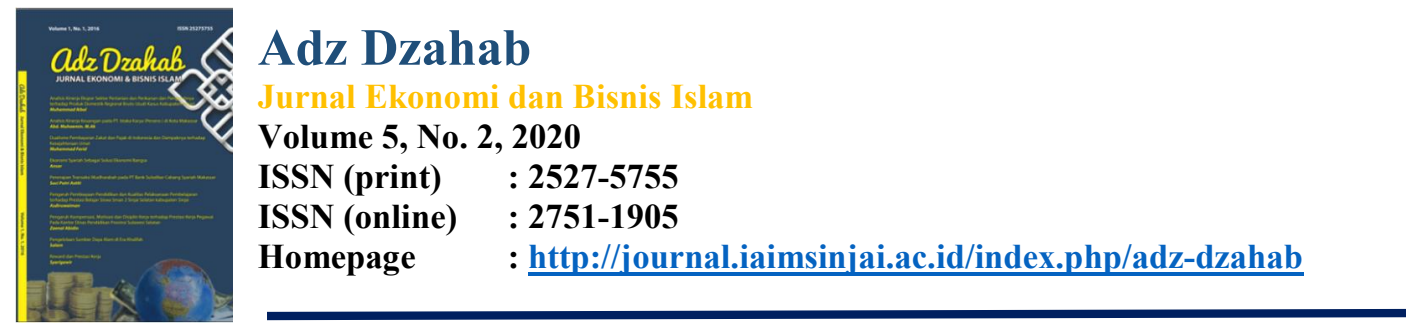

\title{
ANALISIS EKONOMI ISLAM TINGKAT INPUT PRODUKSI INDUSTRI JAHIT DI NGEBEL KAB. PONOROGO
}

\author{
Rahma Puji Lestari \\ IAIN Ponorogo, Jl. Puspita Jaya, Krajan, Pintu, Kec. Jenangan, Ponorogo \\ Korespondesi Penulis. E-mail: rahmap293@gmail.com, Tlp: +6285745065120
}

\begin{abstract}
Abstrak
Dalam kehidupan sehari-hari, manusia berperan sebagai konsumen dari barang kebutuhan yang tentunya beragam antar individu. Barang kebutuhan tersebut tentunya berasal dari hasil produksi. Tujuan analisis ini ialah untuk mengetahui seberapa besar pengaruh faktor produksi, input bahan baku, penerapan produksi dan segala yang berpengaruh terhadap kegiatan produksi jahit di Ngebel Ponorogo dengan perspektif Ekonomi Islam. Ruang lingkupnya mencakup mengenai hasil data sekunder dari produksi yang dikaitkan dengan teori-teori produksi Ekonomi Islam yang ada. Khususnya dalam usaha produksi usaha jahit yang dianalisis dalam laporan ini. Metode penelitian yang digunakan adalah dengan menganalisa dari data sekunder tentang produksi. Data tersebut yang kemudian diolah sedemikian rupa agar menjadi laporan yang baik dan relevan. Hasil laporan ini berguna untuk mengetahui apakah teori produksi yang ada selama ini berkaitan dan terbukti sama dengan kegiatan produksi yang ada di dunia nyata. Hasil dari laporan ini menunjukan beberapa penerapan tentang teori produksi dalam kehidupan, seperti faktor-faktor produksi mulai dari tenaga kerja yang ada, modal yang dimiliki, sumber daya produksi, laporan ini juga menunjukan kuantitas barang yang diproduksi saat pendemi Covid-19 ini, juga ada penjabaran tujuan dari produksi barang itu sendiri seperti memenuhi kebutuhan rumah tangga, untuk mendapatkan keuntungan, untuk meningkatkan kemakmuran bersama.
\end{abstract}

Kata Kunci: Produksi, Input produksi, Tujuan produksi

\begin{abstract}
In everyday life, humans act as consumers of necessities which of course vary between individuals. These necessities of course come from production. The purpose of this analysis is to determine how much influence the factors of production, raw material input, production implementation and all that affect the sewing production activities in Ngebel Ponorogo with an Islamic economic perspective. Its scope includes the results of secondary data from production associated with existing Islamic Economics production theories. Especially in the sewing business production business that is analyzed in this report. The research method used is to analyze the secondary data about production. The data is then processed in such a way as to become a good and relevant report. The results of this report are useful for finding out whether existing production theories are related and proven to be the same as production activities in the real world. The results of this report show several applications of production theory in life, such as factors of production starting from existing labor, owned capital, production resources, this report also shows the quantity of goods produced during the Covid-19 pandemic, there are also elaboration of the objectives of the production of the goods themselves, such as meeting household needs, for profit, to increase mutual prosperity.
\end{abstract}

Keywords: Production, Production inputs, Production objectives 


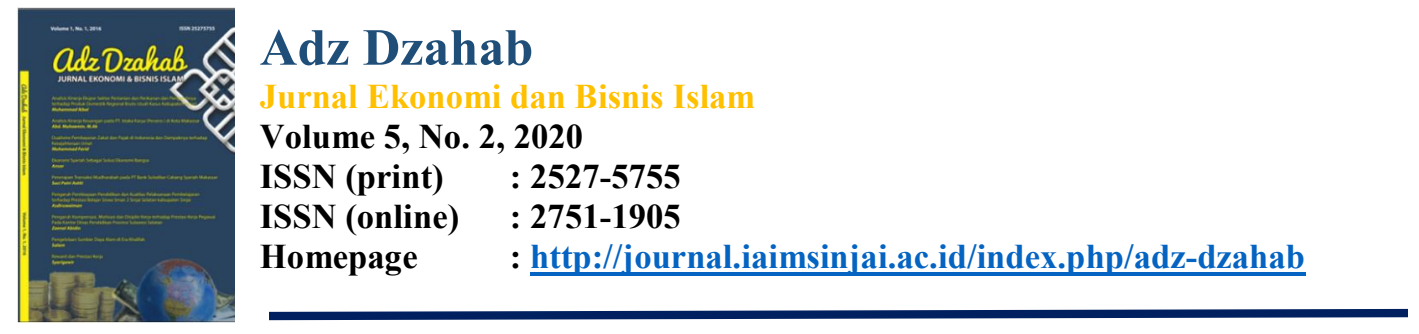

\section{Pendahuluan}

Istilah produksi sering digunakan dalam membuat sesuatu. Secara khusus, produksi adalah kegiatan untuk menciptakan atau menambah suatu barang atau jasa. Dalam istilah yang lebih luas dan lebih fundamental, produksi dapat diartikan sebagai pengubahan bahan-bahan dari sumber-sumber menjadi hasil yang diinginkan oleh konsumen, hasil itu dapat berupa barang atau jasa. (Abd. Aziz, 2008:6).

Produksi adalah suatu kegiatan yang dilakukan untuk menambah nilai guna suatu barang dan dapat pula diartikan sebagai upaya untuk mengubah input menjadi output. Produsen adalah individu atau kelompok yang melakukan kegiatan produksi. Produksi berarti kegiatan menghasilkan atau menciptakan barang dan jasa. Sedangkan, barang atau jasa yang dihasilkan dari produksi disebut produk. Lengkapnya, pengertian produksi adalah kegiatan yang dilakukan oleh orang atau badan (produsen) untuk menghasilkan atau menambah nilai guna suatu barang atau jasa. Sebagai contoh, penjahit bekerja untuk menghasilkan barang dan jasa serta koki memasak bahan makanan untuk menghasilkan makanan.

Produksi merupakan kegiatan yang berkaitan dengan cara bagaimana sumber daya (masukan) dipergunakan untuk menghasilkan produk. Produksi merupakan hasil akhir dari proses atau aktivitas ekonomi dengan memanfaatkan beberapa masukan atau input (Joesron dan Fathorrozi, 2003). Produksi atau memproduksi menambah kegunaan (nilai guna) suatu barang. (Isnaini Halimah, 2017:39). Kegunaan suatu barang akan bertambah bila memberikan manfaat baru atau lebih dari bentuk semula. Lebih spesifik lagi produksi merupakan suatu dalam kegiatan perusahaan dengan mengkombinasikan berbagai input untuk menghasilkan output dengan biaya minimum.

Fungsi produksi adalah kaitan antara jumlah output maksimum yang bisa dilakukan masing-masing dan tiap perangkat input (Samuelson, 2002). Fungsi ini tetap untuk tiap tingkatan teknologi yang digunakan. Fungsi produksi ditetapkan oleh teknologi yang tersedia, yaitu hubungan masukan/keluaran untuk setiap sistem produksi adalah fungsi dari karakteristik alat teknologi, peralatan, tenaga kerja, bahan dan sebagainya yang dipergunakan perusahaan.

Ekonomi produksi adalah berhubungan dengan pilihan proses produksi alternatif, seperti pilihan jenis produksi yang akan di lakukan dan lokasi sumber daya yang di kuasai. Juga mengacu pada kegiatan yang berhubungan dengan usaha penciptaan dan penambahan kegunaan atau utilitas. Seberpa jumlah dan jenis yang akan di produksi serta bagaimana mengkombinasi sumberdaya secara optimal merupakan isi pokok bagi masalah produksi, baik pada tingkat perusahaan, industri, maupun masyarakat petani dan nelayan (Aris, 2012).

Dalam ekonomi Islam berpendapat, produksi adalah penyediaan barang dan jasa dengan memperhatikan nilai-nilai keadilan dan kebijakan atau manfaat (mashlahah) bagi masyarakat. Dalam pandangannya, sepanjang produsen telah bertindak adil dan membawa kebijakan bagi masyarakat maka ia telah bertindak Islami Islam menganjurkan umatnya untuk memproduksi dan berperan dalam berbagai bentuk aktivitas ekonomi antara lain: pertanian, perkebunan, perikanan, 


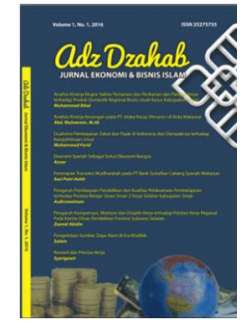

Adz Dzahab

Jurnal Ekonomi dan Bisnis Islam

Volume 5, No. 2, 2020

ISSN (print) : 2527-5755

ISSN (online) : 2751-1905

Homepage : $\quad$ http://journal.iaimsinjai.ac.id/index.php/adz-dzahab

perindustrian, dan perdagangan. Islam memberkahi pekerjaan dunia dan menjadikannya bagian dari ibadah dan jihad, jika sang pekerja bersikap konsisten terhadap peraturan Allah, suci niatnya, dan tidak melupakan kewajiban-Nya.

Tujuan produksi yang pertama sangat jelas, yaitu pemenuhan kebutuhan manusia. Hal ini akan menimbulkan dua implikasi yaitu pertama produsen hanya menghasilkan barang dan jasa yang menjadi kebutuhan, meskipun belum tentu keinginan konsumen karena keinginan manusia sifatnya tidak terbatas sehingga sering kali mengakibatkan ketidakjelasan antara keinginan dan apa yang benarbenar menjadi kebutuhan hidupnya. Barang dan jasa yang dihasilkan harus memiliki manfaat riil bagi kehidupan bukan sekedar memberikan kepuasan maksimum saja. Dalam konsep maslahah, salah satu formulanya adalah harus memenuhi unsur manfaat. Kedua, kuantitas produk yang diproduksi tidak akan berlebihan, tetapi hanya sebatas kebutuhan yang wajar.

Tujuan lainnya yaitu pemenuhan sarana bagi kegiatan sosial dan ibadah kepada Allah, dan inilah tujuan produksi yang tidak akan mungkin dapat tercapai dalam ekonomi konvensional yang bebas nilai. Tujuan produksi adalah mendapatkan berkah yang secara fisik belum tentu dirasakan oleh produsen itu sendiri. Tujuan ini akan membawa implikasi yang luas, sebab produksi tidak akan selalu menghasilkan keuntungan materiil, namun harus mampu pula memberikan keuntungan bagi orang lain dan agama (M. Nur Rianto dan Euis Amelia, 2010:152).

Nyaris seluruh negara selalu untuk memprioritaskan sektor industri. Sektor industri dipandang bagaikan sektor yang mempunyai peringkat produktivitas yang tinggi, sehingga dari unggulnya sektor industry pasti didapatkan nilai tambah tinggi pula yang kemudian target untuk mewujudkan kemakmuran rakyat secara ekonomi akan segera terwujud (Arifin, 2016). Analisa laporan ini dilakukan karena adanya perbedaan antara setiap kegiatan ekonomi produksi antar masyarakat, dan untuk memastikan teori produksi yang ada selama ini sama dan berhubungan dengan kegiatan produksi yang ada di kehidupan yang ada di sehari-hari.

\section{Metode Penelitian}

a. Jenis penelitian

Jenis penelitian ini meliputi kombinasi antara penelitian pustaka (library research), beberapa data sekunder, dan penelitian lapangan dengan metode kualitatif (qualitative method) yang dilakukan pada bulan April 2020. Penelitian pustaka dengan mengkaji dokumen-dokumen yang berhubungan dengan penelitian ini, berupa bahan data dari narasumber, data yang diperoleh melalui buku-buku, jurnal ilmiah dan bahan tertulis lainnya.

. Penelitian kualitatif bertujuan mengembangakan konsep sensitivitas pada masalah yang dihadapi, menerangkan realitas yang berkaitan dengan penelusuran teori dari bawah dan mengembangkan pemahaman akan satu atau lebih dari fenomena yang dihadapi. Dalam penelitian kualitatif yang menjadi instrumen atau alat penelitian adalah peneliti sendiri. Peneliti sebagai human instrument berfungsi menetapkan fokus penelitian, memilih informasi sebagai sumber data, melakukan pengumpulan data, menilai kualitas data, analisis data, menafsirkan dan membuat kesimpulan atas temuannya. ( Imam Gunawan, 2016:80).

b. Pendekatan penelitian 


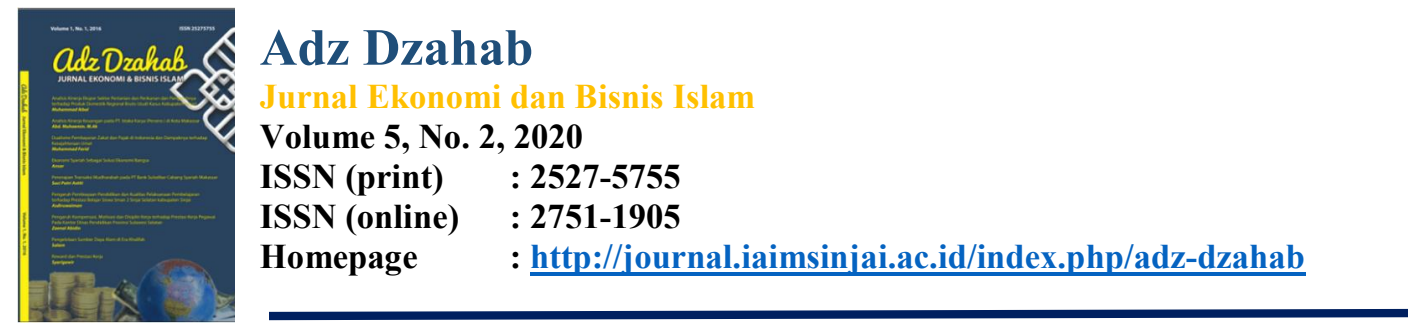

Penelitian studi kasus memusatkan diri secara intensif pada satu objek tertentu yang mempelajarinya sebagai suatu kasus. Penelitian studi kasus dimaksudkan untuk mempelajari secara intensif, tentang latar belakang masalah keadaan dan posisi suatu peristiwa atau objek analisis yang sedang berlangsung saat ini, serta interaksi lingkungan unit sosial tertentu yang bersifat apa adanya. Subjek penelitian dapat berupa individu, kelompok, institusi atau masyarakat.

c. Subjek Penelitian

Adapun yang menjadi subjek pada penelitian ini adalah sebuah usaha industri jahit yang ada di Desa Ngebel, Kabupaten Ponorogo.

d. Objek penelitian

Dalam penelitian ini, yang menjadi objek penelitian adalah tingkat input dan output dari produksi industri jahit yang ada di Ngebel kabupaten Ponorogo, serta tambahan pembahasan mengenai dampak pandemi Covid-19 terhadap industri tersebut.

e. Teknik pengumpulan data

1) Metode interview (wawancara)

Artinya proses tanya-jawab dalam penelitian yang berlangsung secara lisan dalam dimana dua orang atau lebih bertatap muka mendengarkan secara langsung informasi atau keterangan lainnya. Teknik wawancara diawali dengan melakukan persiapan pertanyaan yang sesuai dengan rumusan masalah yang diteliti. Kemudian mendesain pertanyaan secara terstruktur maupun tidak terstuktur.

2) Data sekunder

Data sekunder merupakan informasi-informasi yang dikumpulkan untuk kepentingan studi yang sedang dilakukan oleh peneliti untuk beberapa tujuan tertentu.

3) Dokumentasi

Dokumentasi merupakan sumber data yang digunakan untuk melengkapi penelitian, baik berupa sumber tertulis, film, gambar (foto), dan karya-karya monumental, yang semuanya itu memberikan informasi bagi proses penelitian. Dokumentasi berasal dari dokumen yang berarti sesuatu yang tertulis yang dapat dipakai sebagai alat bukti atau keterangan.

f. Instrumen Penelitian

Instrumen-instrumen penelitian merupakan alat bantu bagi peneliti dalam mengumpulkan data. Kualitas instrumen akan menentukan kualitas data yang terkumpul. Adapun instrumen yang digunakan pada penelitian ini yaitu sesuai dengan teknik pengumpulan data itu sendiri, dalam penelitian ini terdapat beberapa teknik pengumpulan data yaitu sebagai berikut:

1) Panduan observasi adalah alat bantu yang dipakai sebagai pedoman dari pengumpulan data pada proses penelitian.

2) Pedoman wawancara adalah alat bantu yang berupa daftar-daftar dari lembar pertanyaan yang dipakai dalam mengumpulkan data.

3) Data dokumentasi adalah catatan peristiwa dalam bentuk tulisan langsung, instrumen penilaian, foto kegiatan pada saat penelitian.

g. Teknik Analisa Data 


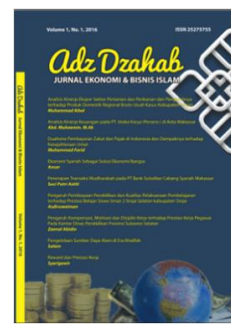

Teknik analisis dan interpretasi yang digunakan adalah teori Haberman dan Miles dikutip oleh Bungin teknik ini dikenal dengan istilah teknik pengolahan data interaktif (Burhan Bungin, 2009:15). Analisis data adalah proses mencari dan menyusun secara sistematis data yang diperoleh dari hasil wawancara, catatan lapangan, dan dokumentasi, dengan cara mengorganisasikan data ke dalam kategori, menjabarkan ke dalam unit-unit, melakukan sintesa, menyusun ke dalam pola, memilih mana yang penting dan yang akan dipelajari, dan membuat kesimpulan sehingga mudah dipahami oleh diri sendiri maupun orang lain (Sugiono, 2010:244). Adapun tahap-tahap dalam penganalisaan data penelitian ini meliputi tiga tahap yaitu sebagai berikut:

1) Reduksi Data (Data Reduction)

Reduksi data, yaitu proses pengumpulan data yang kemudian dilakukan pemilahan, diklasifikasi, serta pemusatan perhatian pada penyederhanaan data. Karena itu data yang diambil adalah data-data yang berkaitan dengan permasalahan yang diteliti. Penelitian ini berkaitan dengan tingkat input dan output dari produksi industri jahit yang ada di Ngebel kabupaten Ponorogo, serta tambahan pembahasan mengenai dampak pandemi Covid-19 terhadap industri tersebut.

2) Penyajian data (Data Display)

Setelah data direduksi, maka langkah selanjutnya adalah men-display data. Dalam penelitian kualitatif, penyajian data bisa dilakukan dlam bentuk uraian singkat, bagan hubungan antara kategori, flouchard dan sejenisnya.

3) Verifikasi (Conclusion Drawing)

Langkah ketiga yang harus dilakukan dalam analisis data kualitatif yakni penarikan kesimpulan dan verifikasi kesimpulan awal yang dikemukakan masih bersifat sementara, dan akan berubah bila tidak ditemukan bukti-bukti berikutnya. Tetapi apabila kesimpulan yang dikemukakan pada tahap awal didukung oleh bukti-bukti wild dan konsisten saat penulis kembali kelapanganmengumpulkan data maka kesimpulan yang dikemukakan merupakan kesimpulan yang kredibel.

\section{Hasil dan Pembahasan}

Pada pembahasan ini penulis akan menguraikan tentang tingkat input dan output dari produksi industri jahit yang ada di Ngebel kabupaten Ponorogo, serta tambahan pembahasan mengenai dampak pandemi Covid19 terhadap industri tersebut. Berikut ini adalah data pemilik dari usaha tersebut:

a. Data Pemilik

Nama Responden

Umur

: Bapak Hartono

Alamat : 55 tahun

: Dusun Sobo, RT 02/RW 01 Desa Ngebel,

Barang produksi : Pakaian/ Jahit Baju

Dari penelitian yang dilakukan, peneliti menemukan faktor-faktor yang mempengaruhi pola produksi dari contoh industri yang ada, terutama dalam kondisi pandemi Covid-19 ini. Berikut ini penjabaran data produksi 


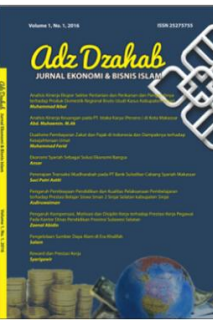

Adz Dzahab

Jurnal Ekonomi dan Bisnis Islam

Volume 5, No. 2, 2020

ISSN (print) : 2527-5755

ISSN (online) : 2751-1905

Homepage : $\quad$ http://journal.iaimsinjai.ac.id/index.php/adz-dzahab

sebelum terjadi pandemi Covid-19 yang datanya berasal dari wawancara pemilik usaha jahit:

b. Data Tingkat Produksi Sebelum Pandemi Covid-19

Tabel 1. Data Total Produksi

\begin{tabular}{|l|c|c|c|c|c|}
\hline No. & Produksi ke- & $\begin{array}{c}\text { Jumlah } \\
\text { Produksi }\end{array}$ & $\begin{array}{c}\text { Harga per } \\
\text { Unit }\end{array}$ & HPP & Ket \\
\hline 1. & 1 & 40 & $\operatorname{Rp} 90.000$ & $\operatorname{Rp} 50.000$ & \\
\hline 2. & 2 & 50 & $\operatorname{Rp} 90.000$ & $\operatorname{Rp~50.000~}$ & \\
\hline 3. & 3 & 65 & $\operatorname{Rp} 90.000$ & $\operatorname{Rp} 50.000$ & \\
\hline 4. & 4 & 47 & $\operatorname{Rp} 90.000$ & $\operatorname{Rp} 50.000$ & \\
\hline 5. & 5 & 60 & $\operatorname{Rp} 90.000$ & $\operatorname{Rp} 50.000$ & \\
\hline
\end{tabular}

(Sumber: Wawancara Bapak Hartono, Pemilik Usaha Jahit, 22 April 2020)

Tabel 2. Data Input Tetap

\begin{tabular}{|l|l|c|c|c|}
\hline No. & \multicolumn{1}{|c|}{$\begin{array}{c}\text { Nama } \\
\text { Input }\end{array}$} & Jumlah & $\begin{array}{c}\text { Harga Per Unit } \\
(\mathrm{Rp})\end{array}$ & $\begin{array}{c}\text { Umur } \\
\text { Ekonomis }\end{array}$ \\
\hline 1. & Meteran & 7 & Rp. 20.000 & 5 tahun \\
\hline 2. & Setrika & 5 & Rp. 250.000 & 6 tahun \\
\hline 3. & Mesin obras & 5 & Rp. 165.000 & 6 tahun \\
\hline 4. & Mesin Jahit & 10 & Rp. 300.000 & 4 tahun \\
\hline 5. & $\begin{array}{l}\text { Gunting } \\
\text { pakaian }\end{array}$ & 15 & Rp. 15.000 & 3 tahun \\
\hline
\end{tabular}

(Sumber: Wawancara Bapak Hartono, Pemilik Usaha Jahit, 22 April 2020)

Tabel 3. Data Input Variabel

\begin{tabular}{|l|c|l|c|c|c|}
\hline No & Produksi & \multicolumn{1}{|c|}{ Nama } & $\begin{array}{c}\text { Harga per } \\
\text { Unit }\end{array}$ & $\begin{array}{c}\text { Jumlah } \\
\text { Tahapan } \\
\text { Produksi }\end{array}$ & Ket \\
\hline 1. & 1 & Benang & Rp 30.000 & 20 & \\
\cline { 3 - 6 } & & $\begin{array}{l}\text { Pewarna } \\
\text { pakaian }\end{array}$ & $\mathrm{Rp} \mathrm{150.000}$ & 10 & \\
\cline { 3 - 6 } & $\begin{array}{l}\text { Kancing } \\
\text { baju }\end{array}$ & $\mathrm{Rp} \mathrm{20.000}$ & 10 & \\
\cline { 3 - 6 } & Kain & $\mathrm{Rp} \mathrm{25.000}$ & $35 \mathrm{~m}$ & \\
\hline \multirow{2}{*}{2} & Benang & $\mathrm{Rp} \mathrm{30.000}$ & 25 & \\
\cline { 3 - 6 } & $\begin{array}{l}\text { Pewarna } \\
\text { pakaian }\end{array}$ & $\mathrm{Rp} \mathrm{50.000}$ & 25 & \\
\cline { 3 - 7 } & $\begin{array}{l}\text { Kancing } \\
\text { baju }\end{array}$ & $\mathrm{Rp} \mathrm{20.000}$ & 25 & \\
\cline { 3 - 6 } & Kain & $\mathrm{Rp} \mathrm{25.000}$ & $55 \mathrm{~m}$ & \\
\hline
\end{tabular}




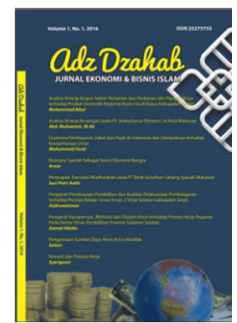

Adz Dzahab

Jurnal Ekonomi dan Bisnis Islam

Volume 5, No. 2, 2020

ISSN (print) : 2527-5755

ISSN (online) : :2751-1905

Homepage : http://journal.iaimsinjai.ac.id/index.php/adz-dzahab

\begin{tabular}{|c|c|c|c|c|}
\hline \multirow[t]{4}{*}{3 . } & \multirow[t]{4}{*}{3} & Benang & Rp 30.000 & 35 \\
\hline & & $\begin{array}{l}\text { Pewarna } \\
\text { pakaian }\end{array}$ & Rp 50.000 & 40 \\
\hline & & $\begin{array}{l}\text { Kancing } \\
\text { baju }\end{array}$ & $\operatorname{Rp} 20.000$ & 35 \\
\hline & & Kain & Rp25.000 & $60 \mathrm{~m}$ \\
\hline & \multirow[t]{4}{*}{4} & Benang & Rp 30.000 & 20 \\
\hline \multirow{3}{*}{4} & & $\begin{array}{l}\text { Pewarna } \\
\text { pakaian }\end{array}$ & Rp 50.000 & 10 \\
\hline & & $\begin{array}{l}\text { Kancing } \\
\text { baju }\end{array}$ & $\mathrm{Rp} 20.000$ & 10 \\
\hline & & Kain & Rp25.000 & $35 \mathrm{~m}$ \\
\hline \multirow[t]{4}{*}{5.} & & Benang & $\operatorname{Rp} 30.000$ & 30 \\
\hline & & $\begin{array}{l}\text { Pewarna } \\
\text { pakaian }\end{array}$ & Rp 50.000 & 38 \\
\hline & & $\begin{array}{l}\text { Kancing } \\
\text { baju }\end{array}$ & $\operatorname{Rp} 20.000$ & 32 \\
\hline & & Kain & Rp25.000 & $55 \mathrm{~m}$ \\
\hline
\end{tabular}

(Sumber: Wawancara Bapak Hartono, Pemilik Usaha Jahit, 22 April 2020)

\begin{tabular}{|c|c|c|c|c|}
\hline \multicolumn{5}{|c|}{ Tabel 4. Data Biaya Input Variabel } \\
\hline $\begin{array}{c}\text { Produksi } \\
\mathrm{Ke}\end{array}$ & Nama bahan & $\begin{array}{l}\text { Harga per } \\
\text { unit }\end{array}$ & Jumlah & Total \\
\hline \multirow[t]{4}{*}{1} & Benang & Rp. 30.000 & 20 & Rp. $\quad 600.000$ \\
\hline & $\begin{array}{l}\text { Pewarna } \\
\text { pakaian }\end{array}$ & Rp. 50.000 & 10 & Rp. 500.000 \\
\hline & $\begin{array}{l}\text { Kancing } \\
\text { baju }\end{array}$ & Rp. 20.000 & 10 & Rp. 200.000 \\
\hline & Kain & Rp. 25.000 & $35 \mathrm{~m}$ & Rp. 875.000 \\
\hline \multicolumn{4}{|c|}{ Jumlah } & Rp.2.175.000 \\
\hline \multirow[t]{3}{*}{2} & Benang & Rp. 30.000 & 25 & Rp. 750.000 \\
\hline & $\begin{array}{l}\text { Pewarna } \\
\text { pakaian }\end{array}$ & Rp. 50.000 & 25 & Rp. 1.250 .000 \\
\hline & $\begin{array}{l}\text { Kancing } \\
\text { baju }\end{array}$ & Rp. 20.000 & 25 & Rp. $\quad 500.000$ \\
\hline
\end{tabular}




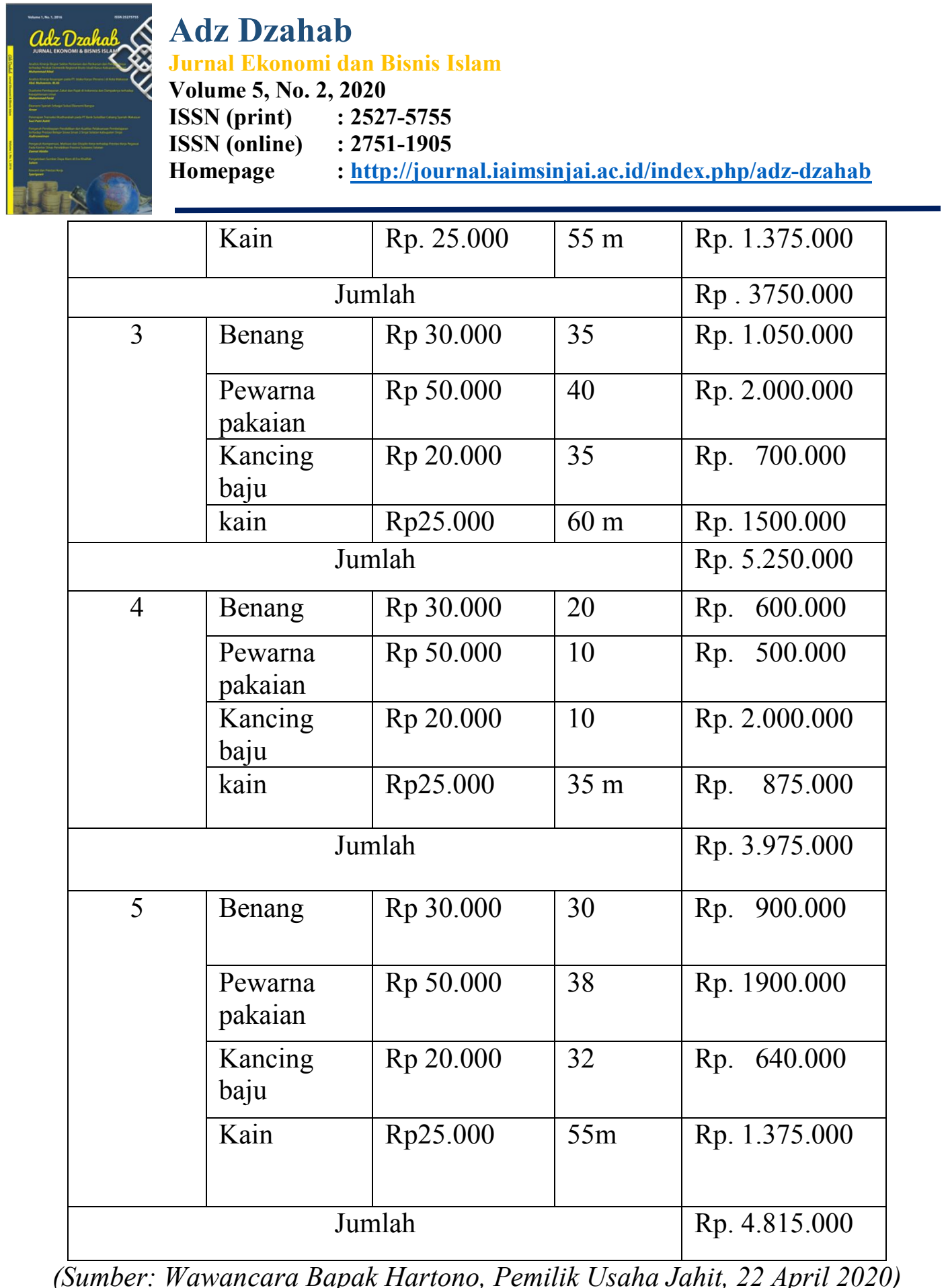

Tabel 5. Data Total Biaya Keuntungan Produksi

\begin{tabular}{|c|c|l|l|l|}
\hline Produksi & Jumlah & Pendapatan & Pengeluaran & Keuntungan \\
\hline 1 & 40 & Rp 3.600.000 & Rp 2.175.000 & Rp. 1.425.000 \\
\hline 2 & 50 & $R p 4.500 .000$ & Rp 3.750.000 & Rp. 750.000 \\
\hline 3 & 65 & $R p 5.850 .000$ & Rp 5.250.000 & Rp. 600.000 \\
\hline 4 & 47 & $R p 4.230 .000$ & Rp 3.975.000 & Rp. 255.000 \\
\hline 5 & 60 & $R p 5.400 .000$ & Rp 4.815.000 & Rp. 585.000 \\
\hline
\end{tabular}




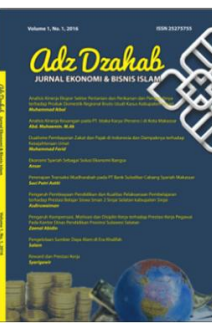

Adz Dzahab

Jurnal Ekonomi dan Bisnis Islam

Volume 5, No. 2, 2020

ISSN (print) : 2527-5755

ISSN (online) : 2751-1905

Homepage : http://journal.iaimsinjai.ac.id/index.php/adz-dzahab

\begin{tabular}{|l|c|c|c|c|c|}
\hline Total & 255 & Rp 23.580.000 & Rp 19.965.000 & Rp. 3.615.000 & \\
\hline
\end{tabular}

(Sumber: Wawancara Bapak Hartono, Pemilik Usaha Jahit, 22 April 2020)

Sedangkan penjabaran data produksi sesudah terjadi pandemi Covid-19 yang disampaikan oleh pemilik usaha Bapak Hartono sebagai berikut ini:

c. Data Tingkat Produksi Sesudah Pandemi Covid-19

Tabel 6. Data Total Produksi

\begin{tabular}{|c|c|c|c|c|c|}
\hline No. & Produksi ke- & $\begin{array}{l}\text { Jumlah } \\
\text { Produksi }\end{array}$ & $\begin{array}{l}\text { Harga per } \\
\text { Unit }\end{array}$ & HPP & Ket \\
\hline 1. & 1 & 25 & $\mathrm{Rp} 90.000$ & $\operatorname{Rp} 55.000$ & HPP naik \\
\hline 2. & 2 & 28 & $\operatorname{Rp} 90.000$ & $\operatorname{Rp} 57.000$ & HPP naik \\
\hline 3. & 3 & 26 & $\operatorname{Rp} 90.000$ & $\operatorname{Rp} 57.000$ & HPP naik \\
\hline 4. & 4 & 30 & $\operatorname{Rp} 90.000$ & Rp 59.000 & HPP naik \\
\hline 5. & 5 & 25 & $\operatorname{Rp} 90.000$ & $\operatorname{Rp} 58.000$ & HPP naik \\
\hline
\end{tabular}

(Sumber: Wawancara Bapak Hartono, Pemilik Usaha Jahit, 22 April 2020)

Tabel 7. Data Input Tetap

\begin{tabular}{|l|l|c|c|c|}
\hline No. & \multicolumn{1}{|c|}{$\begin{array}{c}\text { Nama } \\
\text { Input }\end{array}$} & Jumlah & $\begin{array}{c}\text { Harga Per Unit } \\
(\mathrm{Rp})\end{array}$ & $\begin{array}{c}\text { Umur } \\
\text { Ekonomis }\end{array}$ \\
\hline 1. & Meteran & 7 & Rp. 20.000 & 5 tahun \\
\hline 2. & Setrika & 5 & Rp. 250.000 & 6 tahun \\
\hline 3. & Mesin obras & 5 & Rp. 165.000 & 6 tahun \\
\hline 4. & Mesin Jahit & 10 & Rp. 300.000 & 4 tahun \\
\hline 5. & $\begin{array}{l}\text { Gunting } \\
\text { pakaian }\end{array}$ & 15 & Rp. 15.000 & 3 tahun \\
\hline
\end{tabular}

(Sumber: Wawancara Bapak Hartono, Pemilik Usaha Jahit, 22 April 2020)

Tabel 8. Data Input Variabel

\begin{tabular}{|l|c|l|c|c|c|}
\hline No & Produksi & \multicolumn{1}{|c|}{ Nama } & $\begin{array}{c}\text { Harga per } \\
\text { Unit }\end{array}$ & $\begin{array}{c}\text { Jumlah } \\
\text { Tahapan } \\
\text { Produksi }\end{array}$ & Ket \\
\hline 1. & 1 & Benang & Rp 33.000 & 20 & \\
\cline { 3 - 6 } & $\begin{array}{l}\text { Pewarna } \\
\text { pakaian }\end{array}$ & Rp 52.000 & 10 & \\
\cline { 3 - 6 } & $\begin{array}{l}\text { Kancing } \\
\text { baju }\end{array}$ & Rp 21.000 & 10 & \\
\cline { 3 - 6 } & Kain & Rp 28.000 & $35 \mathrm{~m}$ & \\
\hline 2. & 2 & Benang & Rp 33.000 & 25 & \\
\cline { 3 - 6 } & $\begin{array}{l}\text { Pewarna } \\
\text { pakaian }\end{array}$ & Rp 52.000 & 25 & \\
\hline
\end{tabular}




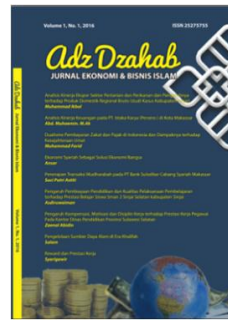

Adz Dzahab

Jurnal Ekonomi dan Bisnis Islam

Volume 5, No. 2, 2020

ISSN (print) : 2527-5755

ISSN (online) : :2751-1905

Homepage : http://journal.iaimsinjai.ac.id/index.php/adz-dzahab

\begin{tabular}{|c|c|c|c|c|}
\hline & & $\begin{array}{l}\text { Kancing } \\
\text { baju }\end{array}$ & $\operatorname{Rp} 21.000$ & 25 \\
\hline & & Kain & $\operatorname{Rp} 28.000$ & $40 \mathrm{~m}$ \\
\hline \multirow[t]{4}{*}{3.} & \multirow[t]{4}{*}{3} & Benang & $\operatorname{Rp} 33.000$ & 20 \\
\hline & & $\begin{array}{l}\text { Pewarna } \\
\text { pakaian }\end{array}$ & Rp 52.000 & 10 \\
\hline & & $\begin{array}{l}\text { Kancing } \\
\text { baju }\end{array}$ & $\operatorname{Rp} 21.000$ & 10 \\
\hline & & Kain & Rp28.000 & $36 \mathrm{~m}$ \\
\hline \multirow[t]{4}{*}{4.} & \multirow[t]{4}{*}{4} & Benang & Rp 33.000 & 25 \\
\hline & & $\begin{array}{l}\text { Pewarna } \\
\text { pakaian }\end{array}$ & Rp 52.000 & 25 \\
\hline & & $\begin{array}{l}\text { Kancing } \\
\text { baju }\end{array}$ & $\operatorname{Rp} 21.000$ & 25 \\
\hline & & Kain & $\operatorname{Rp} 28.000$ & $40 \mathrm{~m}$ \\
\hline \multirow[t]{4}{*}{5.} & \multirow[t]{4}{*}{5} & Benang & $\operatorname{Rp} 33.000$ & 20 \\
\hline & & $\begin{array}{l}\text { Pewarna } \\
\text { pakaian }\end{array}$ & $\operatorname{Rp} 52.000$ & 10 \\
\hline & & $\begin{array}{l}\text { Kancing } \\
\text { baju }\end{array}$ & $\operatorname{Rp} 20.000$ & 10 \\
\hline & & Kain & Rp28.000 & $35 \mathrm{~m}$ \\
\hline
\end{tabular}

(Sumber: Wawancara Bapak Hartono, Pemilik Usaha Jahit, 22 April 2020)

\begin{tabular}{|c|l|l|l|l|}
\hline \multicolumn{5}{|c|}{ Tabel 9. Data Biaya Input Variabel } \\
\hline $\begin{array}{c}\text { Produksi } \\
\text { Ke }\end{array}$ & Nama bahan & $\begin{array}{c}\text { Harga per } \\
\text { unit }\end{array}$ & Jumlah & \multicolumn{2}{c|}{ Total } \\
\hline 1 & Benang & Rp. 33.000 & 20 & Rp 660.000 \\
\cline { 2 - 6 } & $\begin{array}{l}\text { Pewarna } \\
\text { pakaian }\end{array}$ & Rp. 52.000 & 10 & Rp 520.000 \\
\cline { 2 - 6 } & $\begin{array}{l}\text { Kancing } \\
\text { baju }\end{array}$ & Rp. 21.000 & 10 & Rp 210.000 \\
\cline { 2 - 6 } & Kain & Rp. 28.000 & 35 m & Rp 980.000 \\
\hline \multicolumn{2}{|l|}{ Jumlah } & Rp 2.370.000 \\
\hline 2 & Benang & Rp. 33.000 & 25 & Rp 825.000 \\
\hline
\end{tabular}




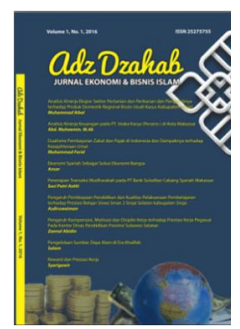

Adz Dzahab

Jurnal Ekonomi dan Bisnis Islam

Volume 5, No. 2, 2020

ISSN (print) : 2527-5755

ISSN (online) : 2751-1905

Homepage : http://journal.iaimsinjai.ac.id/index.php/adz-dzahab

\begin{tabular}{|c|c|c|c|c|}
\hline & $\begin{array}{l}\text { Pewarna } \\
\text { pakaian }\end{array}$ & Rp. 52.000 & 25 & $\mathrm{Rp} 1.300 .000$ \\
\hline & $\begin{array}{l}\text { Kancing } \\
\text { baju }\end{array}$ & Rp. 21.000 & 25 & Rp $\quad 525.000$ \\
\hline & Kain & Rp. 28.000 & $40 \mathrm{~m}$ & RP 1.120 .000 \\
\hline \multicolumn{4}{|c|}{ Jumlah } & Rp 3.770.000 \\
\hline \multirow[t]{4}{*}{3} & Benang & Rp. 33.000 & 20 & Rp $\quad 660.000$ \\
\hline & $\begin{array}{l}\text { Pewarna } \\
\text { pakaian }\end{array}$ & Rp. 52.000 & 10 & Rp $\quad 520.000$ \\
\hline & $\begin{array}{l}\text { Kancing } \\
\text { baju }\end{array}$ & Rp. 21.000 & 10 & $\begin{array}{ll}\mathrm{Rp} & 210.000\end{array}$ \\
\hline & Kain & Rp. 28.000 & $36 \mathrm{~m}$ & Rp 1.008 .000 \\
\hline \multicolumn{4}{|c|}{ Jumlah } & $\operatorname{Rp} 2.398 .000$ \\
\hline \multirow[t]{4}{*}{4} & Benang & Rp. 33.000 & 25 & Rp $\quad 825.000$ \\
\hline & $\begin{array}{l}\text { Pewarna } \\
\text { pakaian }\end{array}$ & Rp. 52.000 & 25 & $\mathrm{Rp} 1.300 .000$ \\
\hline & $\begin{array}{l}\text { Kancing } \\
\text { baju }\end{array}$ & Rp. 21.000 & 25 & $\mathrm{Rp} \quad 525.000$ \\
\hline & Kain & Rp. 28.000 & $40 \mathrm{~m}$ & RP 1.120 .000 \\
\hline \multicolumn{4}{|c|}{ Jumlah } & $\operatorname{Rp} 3.770 .000$ \\
\hline \multirow[t]{4}{*}{5} & Benang & Rp. 33.000 & 20 & $\mathrm{Rp} \quad 660.000$ \\
\hline & $\begin{array}{l}\text { Pewarna } \\
\text { pakaian }\end{array}$ & Rp. 52.000 & 10 & Rp $\quad 520.000$ \\
\hline & $\begin{array}{l}\text { Kancing } \\
\text { baju }\end{array}$ & Rp. 21.000 & 10 & $\mathrm{Rp} \quad 210.000$ \\
\hline & Kain & Rp. 28.000 & $35 \mathrm{~m}$ & $\mathrm{Rp} \quad 980.000$ \\
\hline \multicolumn{4}{|c|}{ Jumlah } & Rp 2.370.000 \\
\hline
\end{tabular}

(Sumber: Wawancara Bapak Hartono, Pemilik Usaha Jahit, 22 April 2020)

Tabel 10. Data Total Biaya Keuntungan Produksi

\begin{tabular}{|c|c|l|l|ll|}
\hline Produksi & Jumlah & Pendapatan & Pengeluaran & Keuntungan \\
\hline 1 & 25 & $\mathrm{Rp} 2.250 .000$ & $\mathrm{Rp} 1.775 .000$ & $\mathrm{Rp} \quad 475.000$ \\
\hline 2 & 28 & $\mathrm{Rp} 2.520 .000$ & $\mathrm{Rp} 1.996 .000$ & $\mathrm{Rp} \quad 524.000$ \\
\hline
\end{tabular}




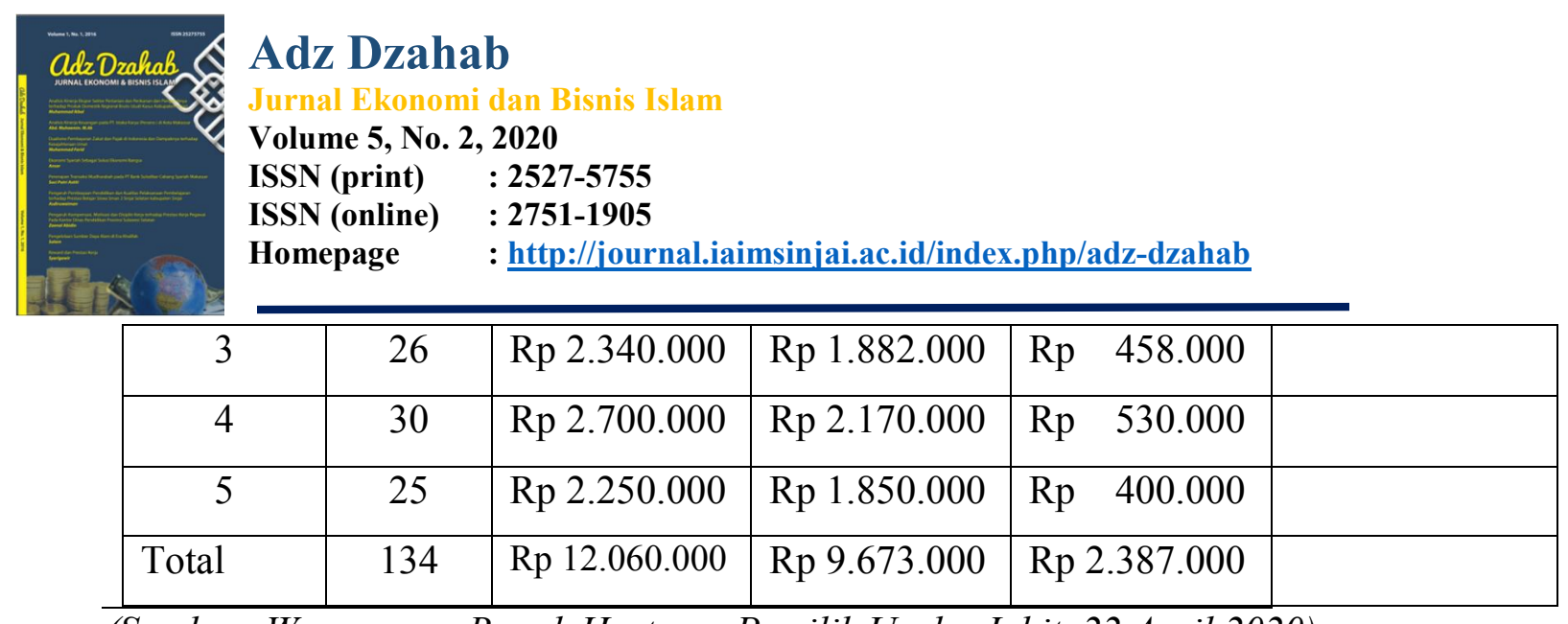

(Sumber: Wawancara Bapak Hartono, Pemilik Usaha Jahit, 22 April 2020)

Dari beberapa data diatas dapat dilihat bahwa harga pokok penjualan dari bahan baku industri menjadi naik akibat pandemi Covid-19 ini. Hal ini sesuai dengan pandemi Covid-19 yang terjadi saat ini mau tidak mau memberikan dampak terhadap berbagai sektor. Pada tataran ekonomi global, pandemic Covid-19 memberikan dampak yang sangat signifikan pada perekonomian domestik negara-bangsa dan keberadaan UMKM. Laporan Organisation for Economic Co-operation and Development (OECD) menyebutkan bahwa pandemi ini berimplikasi terhadap ancaman krisis ekonomi besar yang ditandai dengan terhentinya aktivitas produksi di banyak negara, jatuhnya tingkat konsumsi masyarakat, hilangnya kepercayaan konsumen, jatuhnya bursa saham yang pada akhirnya mengarah kepada ketidakpastian.

d. Produksi

Berdasarkan data yang didapatkan, Bapak Hartono memproduksi pakaian berupa baju dan celana yang diproduksi di rumahnya tepatnya di Desa Ngebel. Bapak Hartono dalam sekali produksi dapat memproduksi hingga 65 unit saat belum terjadi pandemi Covid-19 dan paling sedikit setidaknya 40 unit. Dengan harga pokok penjualannya dalam 1 unit sebesar Rp.50.000 kemudian dijual seharga Rp.90.000.

Sedangkan setelah terjadi adanya pandemi terjadi penurunan tingkat produksi atas usaha bisnis bapak Hartono dalam sekali produksi dapat menurun hingga 25 unit, sama saja setengah dari produksi sebelum pandemi terjadi.Dengan harga pokok penjualannya yang naik dari 1 unit sebesar Rp.58.000 kemudian dijual dengan harga tetap Rp. 90.000, karena agar pelanggan pak Hartono tetap memesan jahitan baju pada Pak Hartono.

Proses produksi baju ini dimulai dari pemilihan kain, menentukan ukuran, pemotongan kain, penjahitan, penambahan aksesoris, dll. Oleh karena itu membutuhkan bermacam-macam alat/masukan (Input) agar bisa menghasilkan baju sesuai yang diinginkan (output). Produksi sendiri secara umum dapat diartikan sebagai suatu kegiatan atau proses yang mentransformasikan masukan (input) menjadi keluaran (output). Sedangkan pengertian produksi dalam ekonomi adalah kegiatan yang berhubungan dengan usaha penciptaan dan penambahan kegunaan atau utilitas suatu barang dan jasa (Nulaela, 2006:12).

Dalam produksi baju ini Bapak Hartono lah yang berperan sebagai produsen. Produsen yaitu siapa saja yang dengan membubuhkan nama, merek, ataupun tanda-tanda lain pada produk. Adapula yang mengartikan 


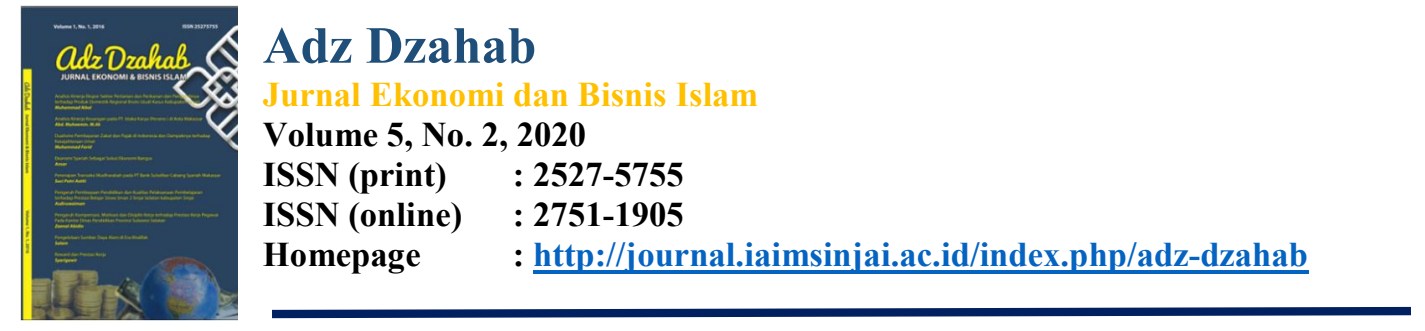

produsen sebagai pihak yang menghasilkan produk akhir berupa barang manufaktur. Produksi pakaian berupa baju oleh Bapak Hartono ini bertujuan untuk mencukupi kebutuhan hidupnya dan keluarga, membantu masyarakat dalam memenuhi kebutuhan akan pakaian atau baju, dan tentunya juga untuk membuka lapangan pekerjaan untuk masyarakat sekitar. Pembelinya pun beragam mulai dari ibu-ibu, bapak-bapak, maupun remaja. Hal ini sesuai denga teori mengenai tujuan produksi yang diantaranya ialah untuk memenuhi kebutuhan rumah tangga keluarga maupun rumah tangga produksi, untuk mndpatkan keuntungan bagi produsen, untuk meningkatkan kemakmuran, dan lain-lainnya.

e. Input Tetap

Dalam data yang kami dapatkan Bapak Hartono membutuhkan berbagai macam bahan dan alat untuk kelangsungan kegiatan produksi baju yang dijalankan. Diantaranya alat yang dibutuhkan, meteran sebab jika tidak ada meteran maka akan kesulitan untuk mengukur besar kecilnya baju yang akan diproduksi, oleh karena itu meteran sangat diperlukan. Selain meteran yang ke dua ada setrika yang mana tentunya setrika ini akan membuat output jadi terlihat lebih rapi. Yang ketiga adalah mesin obras, dengan adanya mesin obras maka hasil obrasan pada baju yang diproduksi akan lebih bagus dari pada obras pakai tangan. selanjutnya yaitu mesin jahit, dalam memproduksi baju tentunya Bapak Hartono sangat membutuhkan mesin jahit karena jika tidak ada mesin jahit maka kelangsungan produksi terhambat atau tidak akan jalan. Dan yang terakhir adalah gunting, gunting ini berperan pada produksi bagian awal maupun akhir, pada bagian awal gunting tentunya untuk memotong kain yang telah diukur sebelumnya, dan pada bagian akhir gunting dapat digunakan untuk merapikan hasil jahitan yang kurang rapi.

Berbagai macam barang yang disebutkan di atas biasa disebut dengan faktor produksi tetap atau input tetap. Meteran, setrika, mesin obras, mesin jahit, dan gunting termasuk pada input tetap, sebab hal ini sesuai dengan teori atau pengertian input tetap. Input tetap adalah input yang jumlahnya tidak berubah, berapapun jumlah output yang diproduksi. Maksudnya berapapun hasil output yang dihasilkan Bapak Hartono, tidak dipengaruhi oleh jumlah dari meteran, setrika, mesin obras, mesin jahit, dan gunting yang dimiliki.

f. Input Variabel

Data yang kami dapatkan dari produksi baju milik Bapak Hartono, terdapat beberapa macam barang atau bahan yang harus ada dalam kelangsungan produksi baju, sebab jika bahan ini tidak ada maka produksi tidak akan berjalan. Beberapa diantaranya yaitu benang, dalam pembuatan baju tentunya harus ada benang, jika tidak ada benang maka baju tidak akan jadi melainkan akan tetap menjadi kain. Yang kedua ada pewarna pakaian, agar hasil atau output yang dihasilkan itu menarik maka bajunya harus diberi warna agar konsumen bisa memilih warna dari baju yang ingin dibeli. Selanjutnya adalah kancing baju, baju walaupun sudah dijahit tetapi tidak 


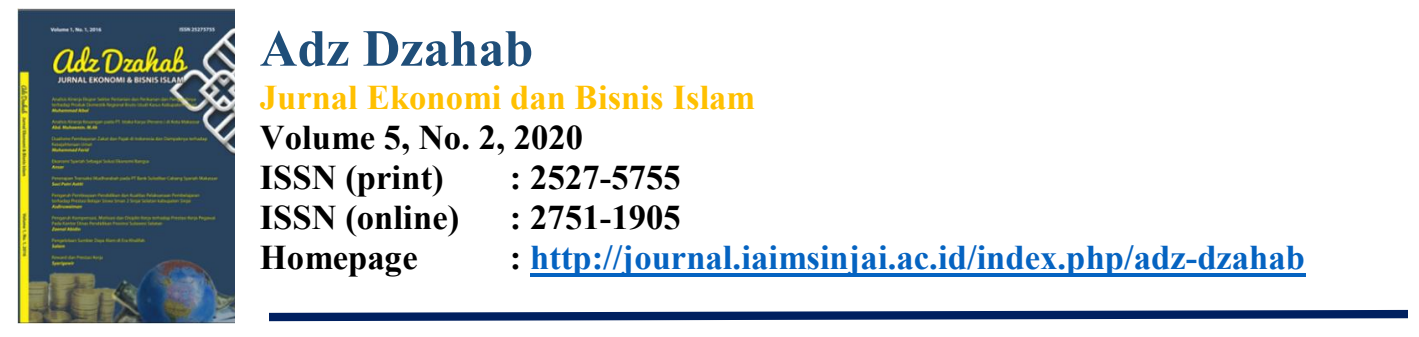

ada kancingya maka dipakai juga tidak akan nyaman sebab tidak menutup badan dengan baik. Yang terakhir adalah kain, kain adalah bahan pokok untuk membuat baju, jika kain tidak ada maka baju juga tidak akan jadi (Dhyah Setyorini, 2008: 128).

Beberapa bahan diatas termasuk pada input variabel. Disebut dengan input variabel karena hal ini sesuai dengan teori atau pengertian dari input variabel, yaitu input yang jumlahnya berubah-ubah mengikuti banyaknya output yang diproduksi. Maksudnya adalah jumlah output yang dihasilkan itu tergantung pada jumlah dari benang, pewarna pakaian, kancing baju, dan kain ini. Jika persediaan bahan-bahan tersebut banyak maka secara otomatis jumlah baju yang diproduksi juga akan banyak, dan begitupun sebaliknya apabila jumlah bahan itu sedikit maka hasil baju yang diproduksi juga sedikit.

\section{Simpulan}

Tingkat produksi yang ada dikala pandemi Covid-19 yang terjadi saat ini cenderung mengalami penurunan yang cukup banyak. Mau tidak mau memberikan dampak terhadap berbagai sector, termasuk pada sector industri dan produksi. Pada tataran ekonomi global, pandemic Covid-19 memberikan dampak yang sangat signifikan pada perekonomian domestik negara-bangsa dan keberadaan UMKM. Laporan Organisation for Economic Co-operation and Development (OECD) menyebutkan bahwa pandemi ini berimplikasi terhadap ancaman krisis ekonomi besar yang ditandai dengan terhentinya aktivitas produksi di banyak negara, jatuhnya tingkat konsumsi masyarakat, hilangnya kepercayaan konsumen, jatuhnya bursa saham yang pada akhirnya mengarah kepada ketidakpastian.

Adanya input tetap dan input variable dalam produksi juga dipengaruhi oleh kondisi saat ini dikala pandemi. Karena adanya pandemi Covid-19 ini sebagian input yang ada dalam produksi mengalami kenaikan harga. Beberapa bahan termasuk pada input tetap dan input variabel di kegiatan produksi Pak Hartono mengalami beberapa perubahan harga karena krisis ekonomi dan tidak stabilnya harga pasar saat Pandemi Covid-19 ini. Disebut dengan input variabel karena hal ini sesuai dengan teori atau pengertian dari input variabel, yaitu input yang jumlahnya berubah-ubah mengikuti banyaknya output yang diproduksi. Contoh input variable dalam produksi bapak Hartono seperti benang, pewarna pakaian, kain dan sebagainya. Begitu juga dengan kegiatan produksi di usaha lain juga mengalami kenaikanharga seperti harga sembako, harga sayur mayor, alat-alat produksi pun ikut naik harganya akibat adanya pandemi Covid-19 ini.

\section{Daftar Pustaka}

\section{Buku:}

Aziz, Abdul. Ekonomi Islam Analisis Mikro dan Makro. Yogyakarta: Graha Ilmu. 2008.

Ali, Muhammad. Penelitian Kependidikan Prosedur dan Strategi. Cet. III; Bandung: Angkasa. 2010.

Bungin, Burhan. Analisis Data Kualitatif: Pemahaman Filosofis dan Metodologis ke Arah Penguasaan Model Aplikasi. Cet. III; Jakarta: Rajawali Press. 2009. 


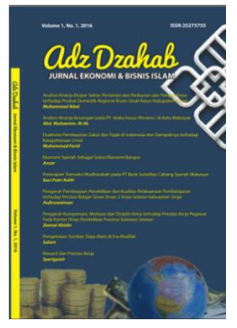

Adz Dzahab

Jurnal Ekonomi dan Bisnis Islam

Volume 5, No. 2, 2020

ISSN (print) : 2527-5755

ISSN (online) : 2751-1905

Homepage : http://journal.iaimsinjai.ac.id/index.php/adz-dzahab

Euis Amalia, dan M. Nur Rianto Al Arif. Teori Mikroekonomi. (Jakarta: Prenada Media Group. 2010.

Purnastuti, Losina. dkk. Ekonomi. Yogyakarta: Grasindo. 2016.

Pusat Pengkajian dan Pengembangan Ekonomi Islam. Ekonomi Islam. Jakarta: PT. RajaGrafindo Persada. 2008.

Rosmawati. Pokok-Pokok Hukum Perlindungan Konsumen. Depok: Prenadamedia Group. 2018.

2008

Setyorini, Dhyah dkk. Cara Mudah UN 08 Ekonomi (Yogyakarta: Grasindo,

Sugiono. Metode Penelitian Kualitatif, Kualitatif dan R\&D. Cet. XI; Bandung: Alfabeta. 2010.

Sukwiaty dkk. Ekonomi. Yogyakarta: Yudhistira. 2010.

Zuriah, Nurul. Metode Penelitian Sosial dan Pendidikan: Teori dan Aplikasinya. Cet. III; Jakarta: PT. Bumi Aksara. 2005.

Jurnal:

Muh. Romi Syahputra, dan Isnaini Halimah Rambe. "Aplikasi Data Envelopment Analysis (Dea) Untuk Pengukuran Efisiensi Aktivitas Produksi” Journal MES Vol. 2. April 2017.

Website:

Imam Gunawan, Metode Penelitian Kualitatif Teori dan Praktik (Cet. IV; Jakarta:

Bumi Aksara. 2016.

Nurlela dkk. Pengantar Bisnis. Jakarta: Gramedia Pustaka Utama. 2006.

OECD, SME Policy Responses 2020, (https://read.oecdilibrary.org/view/?ref=119 119680-di6h3qgi4x\&title=Covid-

19 SME Policy Responses) diakses 10 September 2020. 